\title{
LIVER
}

\section{Tezosentan, an endothelin receptor antagonist, limits liver injury in endotoxin challenged cirrhotic rats}

\author{
W Urbanowicz, P Sogni, R Moreau, K A Tazi, E Barriere, O Poirel, A Martin, M C Guimont, \\ D Cazals-Hatem, D Lebrec
}

See end of article for authors' affiliations

.....................

Correspondence to: Dr D Lebrec, INSERM U481, Hôpital Beaujon, 100 Boulevard du Général Leclerc, 92118 Clichy, France; lebrec@ bichat.inserm.fr

Revised version received 14 April 2004

Accepted for publication 27 April 2004

Background/aims: Lipopolysaccharide (LPS ) induces liver injury which is associated with upregulated endothelin (ET)-1 production. The aim of this study was to investigate the effects of tezosentan, a nonselective ETA and ETB receptor antagonist, in LPS challenged rats with cirrhosis.

Methods: Rats with cirrhosis received LPS and then tezosentan or placebo one hour later. Four hours after LPS administration, rats were killed to measure serum transaminase activity and plasma tumour necrosis factor $\alpha(T N F-\alpha)$ levels. Hepatic inducible nitric oxide synthase (iNOS), myeloperoxidase (MPO), a marker of neutrophil infiltration, and cyclooxygenase (COX)-2 expression were also measured.

Results: LPS administration significantly decreased arterial pressure and significantly increased plasma endothelin levels. Following LPS and tezosentan administration, serum aspartate aminotransferase and alanine aminotransferase activities were similar to those in the control group while they were increased by more than $700 \%$ with LPS alone. Plasma TNF- $\alpha$ levels were significantly lower in rats receiving LPS and tezosentan (182 (38) pg/ml) compared with those receiving LPS alone (821 (212) pg/ml). Tezosentan significantly decreased hepatic MPO activity and hepatic neutrophils but had no effect on LPS induced iNOS or COX-2. Survival rate was significantly higher in rats receiving LPS plus tezosentan (80\%) than in rats receiving LPS alone (50\%).

Conclusion: In LPS challenged cirrhotic rats, tezosentan administration prevents LPS induced liver injury by decreasing intrahepatic neutrophil infiltration. In addition, tezosentan increases survival in these rats.

L cirrhosis, morbidity and mortality due to sepsis is high. ${ }^{1-3}$ Lipopolysaccharide (LPS), from the cell wall of Gram negative bacteria, is the cause of most abnormalities induced by this type of pathogen. ${ }^{1-3}$ During severe endotoxaemia, the liver is crucial because it contains most of the macrophages (Kupffer cells) which eliminate endotoxin, and hepatocytes synthesise the acute phase proteins and enzymes that modulate the inflammatory response. ${ }^{4}$ LPS also contributes to the pathogenesis of liver injury. ${ }^{5}$ Early liver dysfunction is associated with the abnormal release of hepatic enzymes into the circulation and prolonged exposure to cytokines leads to liver failure ${ }^{67}$ Tumour necrosis factor $\alpha$ $(\mathrm{TNF}-\alpha)$ plays a major role, and mortality and liver injury following LPS administration have been shown to be primarily TNF- $\alpha$ dependent. ${ }^{8}{ }^{9}$ In addition, specific sensitivity to LPS has been shown in cirrhosis, associated with a higher mortality and release of TNF- $\alpha$ in the circulation. ${ }^{6}$ However, the exact mechanisms of this phenomenon are unclear but may depend on either the polynuclear infiltrate or the nitric oxide-cyclooxygenase (NO-COX) system.

Endothelin 1 (ET-1), a strong vasoconstrictor of the splanchnic and systemic circulation, plays a role in the portal haemodynamic abnormalities in cirrhosis and in liver damage after ischaemia. ${ }^{10-13}$ Hepatic ET-1 concentrations are increased in cirrhosis and the increased plasma ET-1 levels are probably due to increased hepatic and renal production. ${ }^{14-16}$ However, a decrease in ET-1 metabolism in hepatocytes may also be an important mechanism in cirrhosis. ${ }^{17}{ }^{18}$ The biological effects of ET-1 are mediated by activation of various transduction pathways which probably contribute to these diverse responses. It has been shown that endotoxin administration results in upregulation of the endothelin system $^{19}{ }^{20}$ causing monocytes to produce proinflammatory cytokines such as TNF- $\alpha .{ }^{21}$ These effects of LPS are important in acute endotoxaemia in patients with cirrhosis who have high concentrations of endothelin and a decrease in hepatic NO production. ${ }^{21-23}$

As ET-1 is a major component of LPS induced liver injury in cirrhosis, the aim of this study was to evaluate the effects of tezosentan, a specific non-selective endothelin receptor antagonist, ${ }^{24}$ on liver injury after LPS administration in rats with cirrhosis. Different mechanisms of action were also investigated.

\section{MATERIALS AND METHODS \\ Animals}

Male Sprague-Dawley rats (Charles River Laboratories, SaintAubin-les-Elbeuf, France) were used in the study. Rats underwent bile duct ligation to induce secondary biliary cirrhosis. Surgery was performed under pentobarbital anaesthesia, as previously described. ${ }^{25}$ Briefly, the common bile duct was exposed by median laparotomy and occluded by double ligature with a non-resorbable suture. The common bile duct was then resected between the two ligatures and the abdominal incision closed. Secondary biliary cirrhosis was considered to be present 4-5 weeks after bile duct ligation.

Protocols performed in this laboratory were approved by the French Agriculture Office in conformity with the European legislation for research involving animals.

\footnotetext{
Abbreviations: LPS, lipopolysaccharide; ET, endothelin; TNF- $\alpha$, tumour necrosis factor $\alpha$; NO, nitric oxide; iNOS, inducible nitric oxide synthase; MPO, myeloperoxidase; COX, cyclooxygenase; PBS, phosphate buffered saline; EGTA, ethylene glyco-bi-aminoethylether- $\mathrm{N}$ tetraacetic acid; SDS, sodium dodecyl sulphate; PMSF, phenylmethylsulphonyl flupride
} 
Administration of LPS and tezosentan

Twenty four hours before experiments, rats were anaesthetised with sodium pentobarbital $(100 \mathrm{mg} / \mathrm{kg}$ intraperitoneally). The left femoral vein was cannulated (catheter PE-10; Clay Adams, Maryland, USA) for drug administration and the left femoral artery for mean arterial pressure and heart rate measurements. The following day, conscious and unrestrained rats with secondary biliary cirrhosis were divided into three groups: the control group $(\mathrm{n}=10)$ received a placebo of LPS (isotonic saline) and a placebo of tezosentan (isotonic saline) intravenously one hour later; the LPS group $(n=20)$ received intravenous $1.0 \mathrm{mg} / \mathrm{kg}$ LPS (Escherichia coli lipopolysaccharide serotype 0111:B4) dissolved in isotonic saline and a placebo of tezosentan one hour later; and the LPS plus tezosentan group $(\mathrm{n}=15)$ received intravenous $1.0 \mathrm{mg} / \mathrm{kg}$ LPS and tezosentan $(5 \mathrm{mg} / \mathrm{kg})$ intravenously dissolved in isotonic saline one hour later. Four hours after LPS administration, surviving rats were sacrificed by decapitation. Serum was collected to determine transaminase activities and stored at $-80^{\circ} \mathrm{C}$ for endothelin and TNF- $\alpha$ determination. Liver tissue was rapidly frozen in liquid nitrogen and stored at $-80^{\circ} \mathrm{C}$.

\section{Plasma endothelin levels}

Plasma endothelin levels were determined by ELISA according to the manufacturer's instructions (RD Systems Europe, Abingdon, UK).

\section{Serum transaminase activities}

Serum aspartate aminotransferase and alanine aminotransferase activities were measured with a Hitachi 717 automatic analyser (Roche Diagnostic, Meylan, France).

\section{Plasma TNF- $\alpha$ levels}

Plasma TNF- $\alpha$ levels were determined using a sensitive enzyme linked immunosorbent assay ELISA kit (Biosource International, Camarillo, California, USA) specific for rat TNF- $\alpha$, according to the manufacturer's instructions.

\section{Myeloperoxidase (MPO) in liver tissue}

MPO, a marker of neutrophil infiltration, in liver tissue extracts was measured by an ELISA kit (Merck Eurolab, Strasbourg, France) according to the manufacturer's instructions. ${ }^{26}$ The lower detection limit was $1.6 \mathrm{ng} / \mathrm{mg}$ of protein. Approximately $0.1 \mathrm{~g}$ of excised organ was placed in $1 \mathrm{ml}$ of phosphate buffered saline (PBS) containing a complete protease inhibitor (Roche Diagnostic) and homogenised with a Tissue Taeror (Bioblock Scientific, Illkrich, France). The homogenates then underwent freeze-thaw extraction twice, were centrifuged at $6000 \mathrm{~g}$ for 20 minutes at $4^{\circ} \mathrm{C}$, and the cleared supernatants were used to measure MPO. Protein concentrations in the supernatants were measured by a protein dye binding assay (Life Science, Marnes la Coquette, France). ${ }^{27}$ MPO concentrations in liver extracts were expressed as ng/mg of protein.

\section{Liver histology}

The liver was excised, frozen in liquid nitrogen, and stored at $-80^{\circ} \mathrm{C}$ for subsequent analyses. Part of the tissue was fixed in $10 \%$ paraformaldehyde. Certain liver tissues were directly fixed in formalin. Liver sections were stained with haematoxylin and eosin. The proportion of neutrophil infiltrates were assessed by semiquantitative evaluation.

Hepatic inducible nitric oxide synthase (iNOS) activity NOS activity was measured by converting $\mathrm{L}\left[{ }^{14} \mathrm{C}\right]$ arginine into $\mathrm{L}\left[{ }^{14} \mathrm{C}\right]$ citrulline based on the modified method of Cahill and colleagues. ${ }^{28} 29$ Tissues were homogenised and sonicated (Bioblock Scientific) at $4^{\circ} \mathrm{C}$ in a buffer containing $320 \mathrm{mmol} / \mathrm{l}$ sucrose, $50 \mathrm{mmol} / \mathrm{l}$ Tris HCl, $1 \mathrm{mmol} / \mathrm{l}$ EDTA, $1 \mathrm{mmol} / \mathrm{l}$ DTT, $100 \mu \mathrm{g} / \mathrm{ml}$ phenylmethylsulphonyl flupride (PMSF), $10 \mu \mathrm{g} / \mathrm{ml}$ leupeptin, $10 \mu \mathrm{g} / \mathrm{ml}$ trypsin inhibitor, $2 \mu \mathrm{g} / \mathrm{ml}$ aprotinin, $1 \%$ Nonidet-P40, and $0.1 \%$ sodium dodecyl sulphate (SDS) on ice. Homogenates were centrifuged at $1000 \mathrm{~g}$ for five minutes at $4^{\circ} \mathrm{C}$. The protein concentration of the supernatant was measured as described by Bradford $^{27}$ with bovine serum albumin as standard. Fifty microlitres of the supernatant (50-100 $\mu \mathrm{g}$ protein) were incubated in a total volume of $160 \mu \mathrm{l}$ Tris $\mathrm{HCl}(\mathrm{pH} 7.4)$ containing $1 \mathrm{mmol} / \mathrm{l}$ EDTA, $4 \mu \mathrm{mol} / \mathrm{l}$ tetrahydrobiopterin, $1 \mathrm{mmol} / \mathrm{l} \mathrm{NADPH}$, $50 \mathrm{mmol} / \mathrm{l}$ valine, $5 \mathrm{mmol} / \mathrm{l}$ ethylene glyco-bi-aminoethylether-N-tetraacetic acid (EGTA), $100 \mathrm{nmol} / \mathrm{l}$ calmodulin, and $1 \mu \mathrm{Ci} / \mathrm{ml} \mathrm{L}\left[{ }^{14} \mathrm{C}\right]$ arginine. To determine iNOS independent arginine-citrulline conversion, another parallel reaction was performed with an additional $1 \mathrm{mmol} / \mathrm{l} \mathrm{N}^{\mathrm{W}}$-nitro-Larginine. The reaction was continued for one hour at $25^{\circ} \mathrm{C}$ and stopped by adding $1 \mathrm{ml}$ of ice cold PBS and $3 \mathrm{mmol} / \mathrm{l}$ EGTA (pH 5.5). L $\left[{ }^{14} \mathrm{C}\right]$ citrulline was separated by applying the samples to columns containing Dowex AGW-X8 and eluting them with $1 \mathrm{ml}$ of $1 \mathrm{mmol} / \mathrm{l}$ citrulline. The amount of radioactivity was measured by scintillation counting (Beckmann, Irvine, California, USA). Enzyme activity was expressed as pmol of citrulline formed per mg of proteins per hour.

\section{Hepatic iNOS protein expression}

Liver tissue was homogenised in buffer containing $320 \mathrm{mmol} / \mathrm{l}$ sucrose, $50 \mathrm{mmol} / \mathrm{l} \mathrm{Tris} \mathrm{HCl}$ (pH7.4), $1 \mathrm{mmol} / \mathrm{l}$ EDTA, $0.1 \%$ SDS, $1 \%$ Nonidet P-40, 1 mmol/l DTT, $10 \mu \mathrm{g} / \mathrm{ml}$ trypsin inhibitor, $2 \mu \mathrm{g} / \mathrm{ml}$ aprotinin, $100 \mu \mathrm{g} / \mathrm{ml} \mathrm{PMSF}$. Samples were sonicated three times for 20 seconds (Bioblock Scientific). Homogenates were centrifuged at $12000 \mathrm{~g}$ for five minutes at $4^{\circ} \mathrm{C}$ to remove tissue debris. Total protein concentration was determined ${ }^{27}$ and an aliquot of homogenate was suspended in an SDS sample buffer $(0.5$ Tris HCl (pH 6.8), 10\% glycerol, 3\% SDS, $2 \% \beta$-mercaptoethanol, $30 \mathrm{mmol} / \mathrm{l}$ EDTA, and $0.0025 \%$ bromophenol blue). Equal amounts of the denatured protein bar lane underwent SDS-polyacrylamide gel electrophoresis (10\%). Protein concentrations were between 50 and $100 \mu \mathrm{g}$ per lane. Gels were transferred to nitrocellulose by electroblotting. Nitrocellulose filters were blocked by incubation in 5\% non-fat dry milk, $1 \%$ bovine serum albumin, $0.1 \mathrm{~mol} / \mathrm{l} \mathrm{NaCl}, 0.01 \mathrm{~mol} / \mathrm{l}$ Tris $\mathrm{HCl}$ (pH 7.5 ) and $0.1 \%$ Tween 20 overnight at $4{ }^{\circ} \mathrm{C}$. Blots were then incubated for one hour with specific antisera against iNOS (1/3000) (Transduction Laboratories, Lexington, Kentucky, USA) in the same buffer. Blots were washed six times for 10 minutes in $0.1 \mathrm{~mol} / \mathrm{l} \mathrm{NaCl}, 0.01 \mathrm{~mol} / \mathrm{l}$ Tris $\mathrm{HCl}(\mathrm{pH} 7.5)$, $0.1 \%$ Tween 20 , and thereafter incubated for one hour at $25^{\circ} \mathrm{C}$ with a secondary antibody (antirat Ig, peroxidase linked species specific whole antibody). Blots were again washed six times for 10 minutes. Immunoreactivity was visualised by autoradiography. Autoradiographs were scanned by laser densitometry and liver iNOS protein expression in cirrhotic rats after LPS and LPS plus tezosentan administration was expressed as percentage of liver iNOS expression.

Immunoreactive bands were quantified by video densitometry. Values are given in arbitrary units. Results are expressed as a percentage of control group values (100\%).

\section{Cyclooxygenase 2 (COX-2) immunostaining}

Immunostaining was performed by the avidin-biotin complex technique using the Vectastain ABC-AP kit (Vector Laboratories, Burlingame, California, USA). Briefly, $4 \mu \mathrm{m}$ thick cryostat sections were fixed in acetone and washed in $10 \mathrm{mM}$ sodium phosphate, $\mathrm{pH} 7.5,0.9 \%$ saline (PBS). Nonspecific binding sites were blocked with normal serum from the kit for 10 minutes. The primary goat polyclonal specific antibody to COX-2 (Santa Cruz Biotechnology, Santa Cruz, 
California, USA) was diluted 1:400 and incubated overnight at room temperature. Sections were then incubated with a 1:200 dilution of biotinylated rabbit antigoat IgG for 30 minutes at room temperature. After PBS washes, sections were incubated with the ABC-AP reagent for 30 minutes at room temperature. Sections were rinsed and incubated in alkaline phosphatase substrate solution (Vector Laboratories). Finally, sections were counterstained in haematoxylin for one minute and mounted in immunomount (Shandon, Pittsburg, Pennsylvania, USA). Formalin fixed paraffin embedded sections of human colorectal carcinomas known to have strong immunolabelling for COX-2 were used as a positive control while omission of the primary antibody or incubation with the primary antibody and a blocking peptide served as a negative control.

\section{Substances}

$\mathrm{L}\left[{ }^{14} \mathrm{C}\right]$ arginine was purchased from Amersham (Arlinton Heights, Illinois, USA). All other substances were purchased from Sigma Chemical Co. (Saint Louis, Missouri, USA).

Tezosentan was a generous gift from Dr Martine Clozel (Actelion Pharmaceutical Laboratory, Switzerland).

\section{Statistical analysis}

Results are expressed as mean (SEM). Comparisons between groups were made using two factor ANOVA or the Student's $t$ test, as appropriate. Survival rate was compared using the $\chi^{2}$ test. A probability level of $\mathrm{p}<0.05$ was considered to be significant.

\section{RESULTS}

\section{Mean arterial pressure and heart rate}

LPS administration significantly decreased mean arterial pressure and significantly increased heart rate in both the LPS group and the LPS plus tezosentan group compared with the control group (table 1). This effect was detected one hour after LPS administration. Tezosentan administration had no significant effect on mean arterial pressure compared with LPS alone (table 1).

Measurements were performed every 15 minutes (results were presented as mean for one hour). Cirrhotic rats received either LPS or placebo at one hour and tezosentan or placebo at two hours. In the control group, rats received placebo and placebo, in the LPS group, rats received LPS and placebo, and in the LPS + tezosentan group, rats received LPS and tezosentan.

\section{Plasma endothelin levels}

In the LPS group $(n=4)$, plasma endothelin concentrations were significantly higher than in the control group $(n=4)$

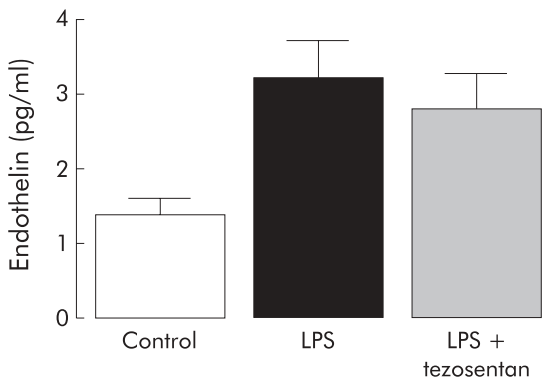

Figure 1 Plasma endothelin levels in the three groups of rats with cirrhosis. Control group, rats received placebo and placebo; LPS group, rats received lipopolysaccharide (LPS) and placebo; LPS + tezosentan group, rats received LPS and tezosentan. There was a significant difference between the LPS group and the control group.
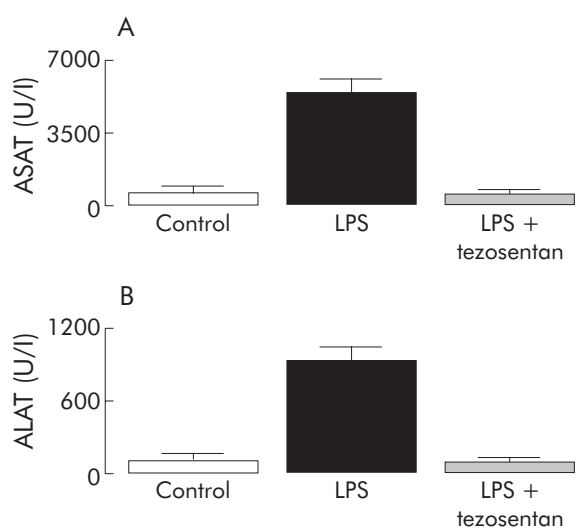

Figure 2 Serum transaminases activity (aspartate aminotransferase (ASAT) (A) and alanine aminotransferase (ALAT) (B)) in the three groups of rats with cirrhosis. Control group, rats received placebo and placebo; LPS group, rats received lipopolysaccharide (LPS) and placebo; LPS + tezosentan group, rats received LPS and tezosentan. The LPS group had significantly higher levels than the LPS + tezosentan and control groups.

(fig 1). In the LPS plus tezosentan group $(n=4)$, plasma endothelin concentrations were not significantly different from the LPS group (fig 1).

\section{Serum transaminase activities}

In the LPS group $(n=7)$, serum transaminase activities were significantly higher than in the control group $(n=9)$ (fig 2). In the LPS plus tezosentan group $(n=10)$, serum

Table 1 Heart rate and mean arterial pressure in the three groups of rats with cirrhosis

\begin{tabular}{|c|c|c|c|c|c|c|}
\hline & \multicolumn{3}{|c|}{ Heart rate (beats/min) } & \multicolumn{3}{|c|}{ Mean arterial pressure $(\mathrm{mm} \mathrm{Hg})$} \\
\hline & $\begin{array}{l}\text { Control } \\
(n=3)\end{array}$ & $\begin{array}{l}\text { LPS } \\
(n=4)\end{array}$ & $\begin{array}{l}\text { LPS }+ \\
\text { tezosentan } \\
(n=6)\end{array}$ & $\begin{array}{l}\text { Control } \\
(n=3)\end{array}$ & $\begin{array}{l}\text { LPS } \\
(n=4)\end{array}$ & $\begin{array}{l}\text { LPS }+ \\
\text { tezosentan } \\
(n=6)\end{array}$ \\
\hline $0-1 \mathrm{~h}$ & 352 (13) & $388(21)$ & $368(8)$ & $97(2)$ & $95(3)$ & $103(3)$ \\
\hline $1-2 h$ & 351 (11) & $400(24)^{*}$ & $425(6)^{*}$ & 102 (5) & $78(4)^{*}$ & $92(4) \dagger$ \\
\hline $2-3 h$ & $372(22)$ & 397 (18) & 411 (16) & 104 (5) & $86(1)^{*}$ & $87(3)^{*}$ \\
\hline $3-4 \mathrm{~h}$ & 347 (4) & 389 (30) & $415(10)^{*}$ & $99(5)$ & $94(7)$ & 92 (5) \\
\hline $4-5 \mathrm{~h}$ & 345 (10) & 389 (31) & $425(10)^{*}$ & $103(2)$ & 93 (10) & $91(8)$ \\
\hline
\end{tabular}

Measurements were performed every 15 minutes (results are presented as mean for one hour).

Cirrhotic rats received either lipopolysaccharide (LPS) or placebo at one hour and tezosentan or placebo at two hours.

Control group, rats received placebo and placebo; LPS group, rats received LPS and placebo; LPS + tezosentan group, rats received LPS and tezosentan.

Values are mean (SEM).

*Significantly different from the control group; †significantly different from the LPS group. 

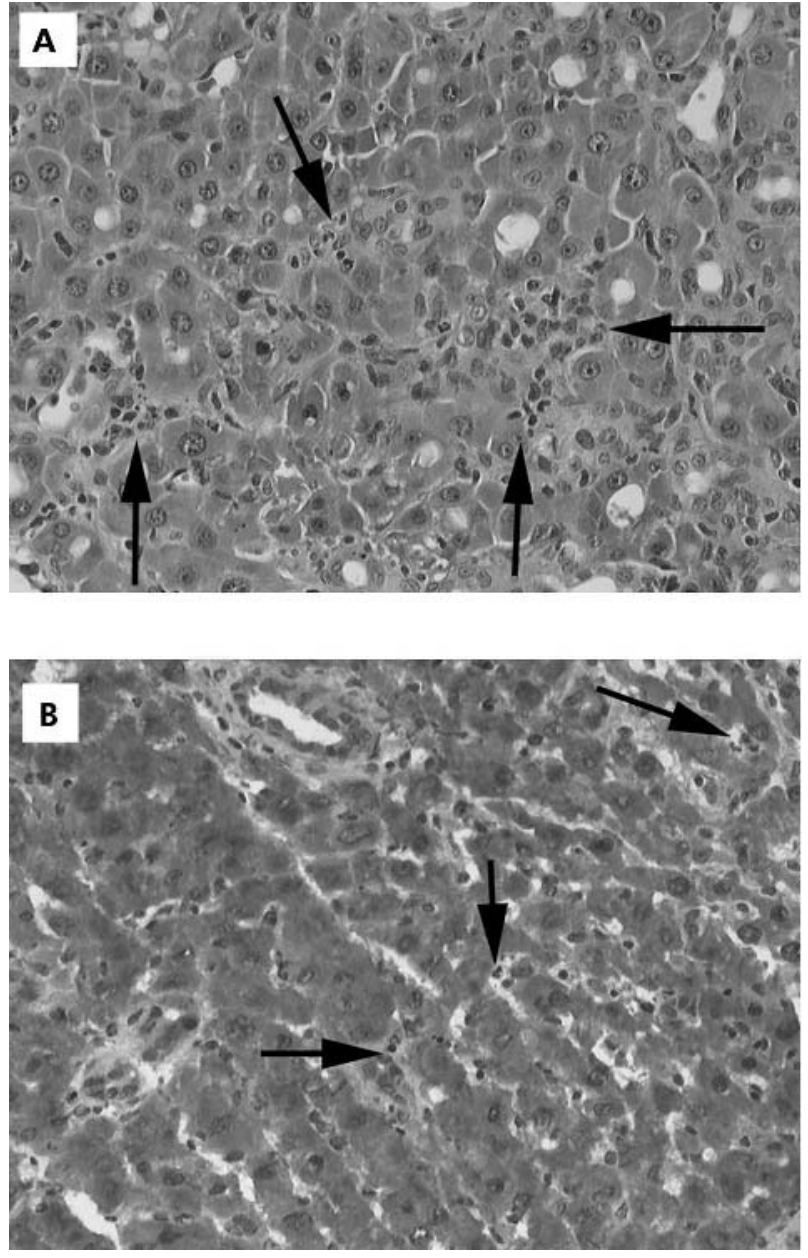

Figure 3 (A) Fixed formalin liver tissue of rats who received lipopolysaccharide (LPS) (haematoxylin and eosin staining $\times 300$ ). Multiple nests of neutrophils are seen between hepatocyłe plates. Arrows indicate the numerous neutrophils. (B) Frozen liver tissue of rat with cirrhosis who received LPS plus tezosentan (haematoxylin and eosin staining). There were few neutrophils in the liver. Arrows indicate the rare infiltrating neutrophils.

transaminase activities were not significantly different from the control group but were significantly lower than in the LPS group (fig 2).

\section{Plasma TNF- $\alpha$ levels}

The mean value for plasma TNF- $\alpha$ levels in the control group $(\mathrm{n}=7)$ was $2.5(0.7) \mathrm{pg} / \mathrm{ml}$. In the LPS group $(\mathrm{n}=6)$, plasma TNF- $\alpha$ levels were significantly higher (821 (212) pg/ml) than in the control group. In the LPS plus tezosentan group $(\mathrm{n}=10)$, plasma TNF- $\alpha$ levels $(182$ (38) pg/ml) were significantly different from both control and LPS groups.

\section{MPO level in liver tissue}

The mean value for hepatic MPO levels in the control group $(\mathrm{n}=7)$ was $23.1(1.8) \mathrm{ng} / \mathrm{mg}$ of protein. In the LPS group $(\mathrm{n}=10)$, hepatic MPO levels were significantly higher $(36.0$ (4.4) $\mathrm{ng} / \mathrm{mg}$ of protein) than in the control group $(\mathrm{p}<0.05)$. There was no significant difference in hepatic MPO levels between the control group and the LPS plus tezosentan group $(\mathrm{n}=8)(18.8(4.1) \mathrm{ng} / \mathrm{mg}$ of protein $)$.

\section{Liver histology}

In the LPS group $(n=3)$, numerous neutrophils were observed in the lobular zone between hepatocyte plates

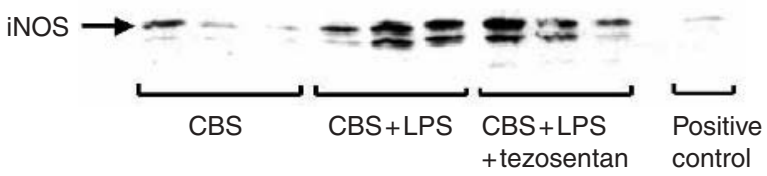

Figure 4 Hepatic inducible nitric oxide synthase (iNOS) hepatic protein expression in the three groups of rats with cirrhosis. CBS group, rats received placebo and placebo; CBS + LPS group, rats received lipopolysaccharide (LPS) and placebo; CBS + LPS + tezosentan group, rats received LPS and tezosentan. Hepatic iNOS hepatic expression was significantly higher in the LPS and LPS plus tezosentan groups than in the control group.

(fig 3A); the number of neutrophils was higher than in the control group $(\mathrm{n}=3)$. In the LPS plus tezosentan group $(\mathrm{n}=3)$, less neutrophils were observed in comparison with the LPS group (fig 3B).

\section{Hepatic iNOS activity}

After LPS administration, hepatic iNOS activity was significantly higher in the LPS group $(n=6)$ (78.2 (7.7) $\mathrm{pmol} / \mathrm{mg}$ of protein/h) and in the LPS plus tezosentan group $(\mathrm{n}=6)(65.1(7.3) \mathrm{pmol} / \mathrm{mg}$ of protein $/ \mathrm{h})$ than in the control group $(\mathrm{n}=6)(49.4 \quad(2.6) \mathrm{pmol} / \mathrm{mg}$ of protein/h). Hepatic iNOS activity was not significantly different between the LPS and LPS plus tezosentan groups.

\section{Hepatic iNOS protein expression}

Hepatic iNOS protein expression was significantly higher after LPS administration in the LPS group $(n=4) \quad(190$ $(21) \%)$ and in the LPS plus tezosentan group $(\mathrm{n}=4)(184$ $(24) \%)$ than in the control group $(n=4)(100 \%)$ (fig 4$)$. There was no significant difference in hepatic iNOS protein expression between the LPS and LPS plus tezosentan groups (fig 4).

\section{COX-2 immunostaining}

COX-2 positivity, estimated in three hepatic samples in each group, increased after LPS administration in the LPS and LPS plus tezosentan groups compared with the control group (fig 5). There was no significant difference in COX-2 positivity between the LPS and LPS plus tezosentan groups. COX-2 was mainly detected in inflammatory and endothelial cells.

\section{Mortality}

In the LPS group, 10 of 20 (50\%) cirrhotic rats died and in the LPS plus tezosentan group three of 15 cirrhotic rats $(20 \%)$ died. There was a significant difference between the two groups $(\mathrm{p}<0.001)$. There was no mortality in the control group.

\section{DISCUSSION}

This is the first study to investigate the effects of tezosentan, a non-selective endothelin receptor antagonist, in LPS challenged rats with cirrhosis. LPS was administered intravenously, followed by intravenous administration of tezosentan or placebo one hour later. Thus the study design mimics the occurrence of severe endotoxaemia by intravenous administration of a Gram negative bacterial product. In this study, normal rats were not investigated as we observed that $1 \mathrm{mg} / \mathrm{kg}$ LPS intravenously had only minor effects on serum transaminase activities and had no lethal effects (unpublished results, Moreau and Lebrec, 2001). Similar findings have been previously observed. ${ }^{67}$

In this series of rats with cirrhosis, LPS administration induced a significant decrease in arterial pressure and an increase in plasma endothelin levels associated with elevated 

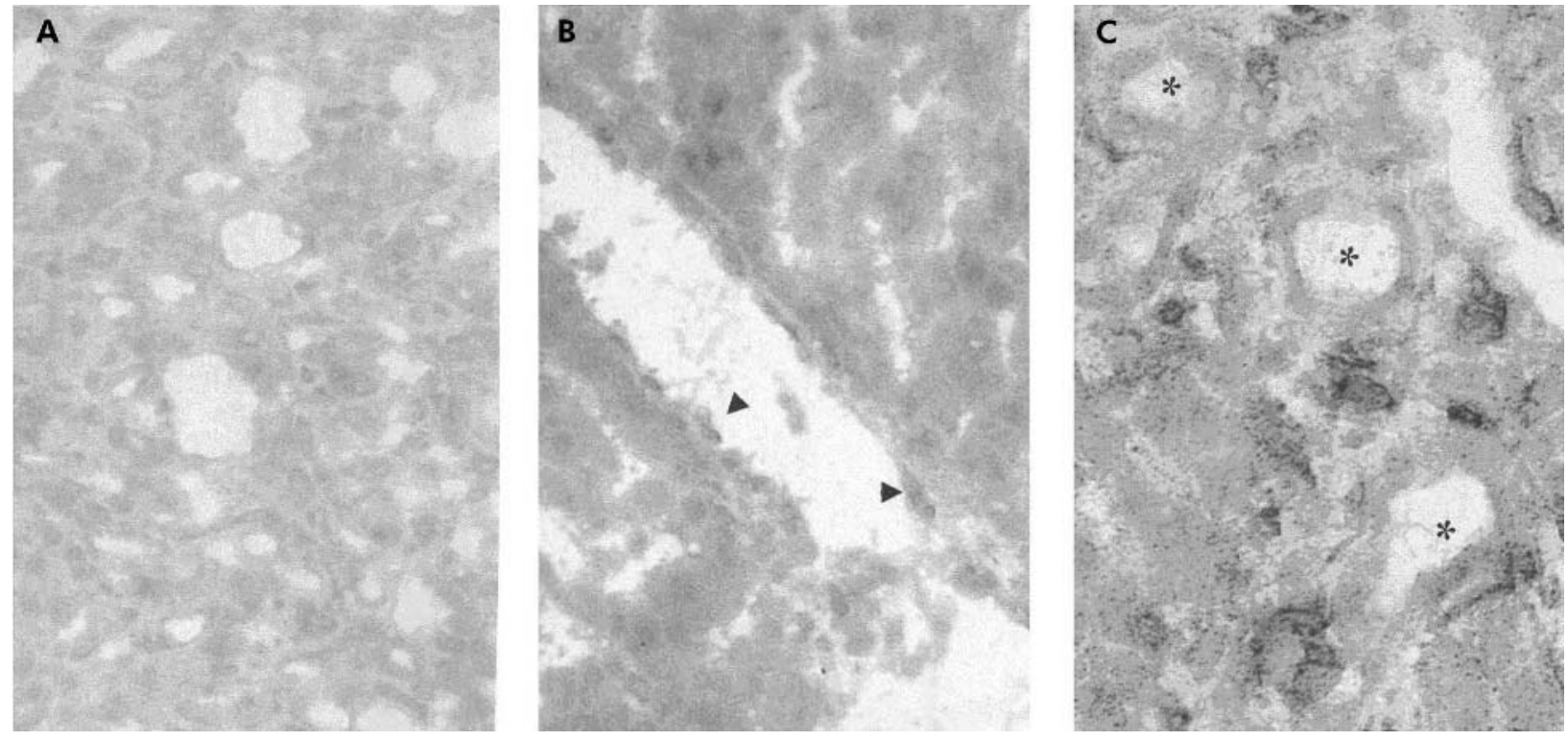

Figure 5 Cyclooxygenase 2 (COX-2) in the three groups of rats with cirrhosis. (A) Control group: COX-2 was not detected. (B) Lipopolysaccharide (LPS) group: COX-2 was positive (arrows). (C) LPS plus tezosentan group, COX-2 was positive ${ }^{*}$ ) and not significantly different from the LPS group.

serum transaminase activities and high mortality indicating endotoxin induced liver injury. These results were similar to those previously observed with similar dosages. ${ }^{6719} 20$ Tezosentan administration did not prevent LPS induced arterial hypotension but did prevent increased serum transaminase activities. This suggests that tezosentan has no systemic haemodynamic effects in LPS challenged rats and that arterial hypotension is not the main cause of liver injury in rats with cirrhosis. The beneficial effects of tezosentan on liver injury were similar to those obtained with an endothelin antagonist in acute hepatic ischaemia/ reperfusion where blockade of both ETA and ETB receptors reduced hepatocellular injury. ${ }^{30}$ On the other hand, our results obtained with this non-selective ETA and ETB receptor antagonist differ from those obtained with a selective ETA receptor antagonist which showed worsening of endotoxin induced hepatic changes and necrosis. ${ }^{31}$ This suggests that endothelin via ETB receptors or the association of both ET receptors plays a major role in the occurrence of liver injury following LPS administration.

LPS stimulates the production of TNF- $\alpha$ in monocytes and macrophages $^{8}$ and TNF- $\alpha$ plays an important role in LPS induced liver injury. The role of TNF- $\alpha$ in liver injury includes triggering apoptosis and necrosis of hepatocytes in vivo ${ }^{8} 92$ and it may have direct cytotoxic effects in human hepatocytes. $^{7}$ In the present study, tezosentan administration limited the increase in serum TNF- $\alpha$ concentrations following LPS administration and thus decreased LPS elicited liver injury. However, the mechanism that causes tezosentan to decrease plasma TNF- $\alpha$ levels remains unclear.

LPS is known to induce significant intrahepatic neutrophil infiltration which plays a role in liver injury. ${ }^{4}$ This was confirmed in this study by the increased intrahepatic neutrophil MPO activity (a marker of neutrophil infiltration) in rats receiving LPS alone. In contrast, rats treated with tezosentan had no increase in intrahepatic neutrophil MPO activity and MPO activity was similar to the control group. Liver histology examination confirms the role of neutrophil infiltration following LPS administration. These findings show that tezosentan prevents LPS induced liver injury, at least in part, by decreasing neutrophil infiltration in the liver.

The exact role of NOS in LPS induced hepatotoxicity has not been clearly established. ${ }^{33}{ }^{34}$ LPS has been shown to induce iNOS and COX-2 in the liver. ${ }^{4}$ NO derived iNOS and proinflammatory prostaglandins produced by $\mathrm{COX}-2$ may play a role in LPS induced liver injury. Thus the prevention of liver injury by tezosentan could be related to iNOS inhibition or COX-2 induction. However, this hypothesis is not supported by our results which showed that iNOS and COX-2 expression were similar in the tezosentan and placebo groups while they were increased in rats receiving LPS alone.

In this study, tezosentan administration markedly and significantly reduced LPS induced mortality. This suggests that activation of endothelin receptors plays a major role in the mechanisms of death induced by endotoxin in rats with cirrhosis. Thus, tezosentan, like various other substances, may reduce the death rate during endotoxin shock. ${ }^{35-39}$ Although the mechanisms of these substances differ, the potential use of a specific non-selective ETA and ETB receptor antagonist might be useful in patients with cirrhosis who develop severe endotoxaemia. Moreover, as tezosentan was administered one hour after LPS, the design of this study mimics clinical conditions and further emphasises the beneficial effects of this antagonist. The exact mechanism of tezosentan on LPS induced mortality remains unknown.

In conclusion, in LPS challenged cirrhotic rats, the use of tezosentan, a specific non-selective ETA and ETB receptor antagonist, prevented LPS elicited liver injury, in part by decreasing intrahepatic neutrophil infiltration. In addition, tezosentan increased survival rate in these rats. The results of the present study suggest that tezosentan administration might be a novel approach to the treatment of endotoxin shock in patients with cirrhosis.

\section{ACKNOWLEDGEMENTS}

Supported by grants from the Association Claude Bernard (WU) and the Association pour la Recherche contre le Cancer (EB). The authors thank Professor J M Launay for measurements of plasma endothelin concentrations.

\section{Authors' affiliations}

W Urbanowicz, P Sogni, R Moreau, K A Tazi, E Barriere, O Poirel,

D Lebrec, Laboratoire d'Hémodynamique Splanchnique et de Biologie Vasculaire, INSERM U-481, Hôpital Beaujon, Clichy, France

A Martin, Service d'Anatomie Pathologique, Hôpital Avicenne, Bobigny, France 
M C Guimont, Service de Biochimie, Hôpital Beaujon, Clichy, France D Cazals-Hatem, Service d'Anatomie et de Cytologie Pathologiques, Hôpital Beaujon, Clichy, France

\section{REFERENCES}

1 Moreau R, Hadengue A, Soupison T. Septic shock in patients with cirrhosis: hemodynamic and metabolic characteristics and intensive care unit outcomes. Crit Care Med 1992;20:746-50.

2 Caly WR, Strauss E. A prospective study of bacterial infection in patients with cirrhosis. J Hepatol 1993; 18:353-8

3 Sogni P, Moreau R, Lebrec D. Endotoxemia: an unnecessary but aggravating condition in portal hypertension? J Hepatol 1999;30:1160-2.

4 Hewett JA, Roth RA. Hepatic and extrahepatic pathobiology of bacterial lipopolisaccharides. Pharmacol Reviews 1993;4:381-404.

5 Paik YH, Schwabe RF, Bataller R, et al. Toll-like receptor 4 mediates inflammatory signaling by bacterial lipopolysaccharide in human hepatic stellate cells. Hepatology 2003;37:1043-55.

6 Heller J, Sogni P, Barriere E, et al. Effects of lipopolysaccharide on TNF- $\alpha$ production, hepatic NOS2 activity, and hepatic toxicity in rats with cirrhosis. $J$ Hepatol 2000;33:376-81.

7 Harry D, Anand R, Holt S, et al. Increased sensitivity to endotoxemia in the bile duct-ligated cirrhotic rat. Hepatology 1999;30:1198-205.

8 Streetz K, Leifeld L, Grundmann D, et al. Tumor necrosis factor alpha in the pathogenesis of human and murine fulminant hepatic failure. Gastroenterology 2000;119:446-60.

9 Papadakis KA, Targan SR. Tumor necrosis factor: biology and therapeutic inhibitors. Gastroenterology 2000;1 19:1148-57.

10 Sogni P, Moreau R, Gomola A, et al. Beneficial hemodynamic effects of bosentan, a mixed $\mathrm{ET}_{\mathrm{A}}$ and $\mathrm{ET}_{B}$ receptor antagonist, in portal hypertensive rats. Hepatology 1998;28:655-9.

11 Goto M, Takei Y, Kawano S, et al. Endothelin-1 is involved in the pathogenesis of ischaemia/reperfusion liver injury by hepatic microcirculatory disturbances. Hepatology 1994;19:675-81.

12 Kawanura E, Yamanaka N, Okamoto E, et al. Response of plasma and tissue endothelin 1 to liver ischemia and its implication in ischemia-reperfusion injury. Hepatology 1995;21:1138-43.

13 Yokoyama Y, Baveja R, Sonin N, et al. Altered endothelin receptor subtype expression in hepatic injury after ischemia/reperfusion. Shock 2000;13:72-8.

14 Gandhi CR, Sproat LA, Subbotin VM. Increased hepatic endothelin-1 levels and endothelin receptor density in cirrhotic rats. Life Sci 1996;58:55-62.

15 Pinzani M, Milani S, De Franco R, et al. Endothelin 1 is overexpressed in human cirrhotic liver and exerts multiple effects on activated hepatic stellate cells. Gastroenterology 1996;110:534-48.

16 Eakes AT, Olson MS. Regulation of endothelin synthesis in hepatic endothelial cells. Am J Physiol 1998;274:G1068-76.

17 Gerbes AL, Moller S, Gulberg V, et al. Endothelin-1 and -3 plasma concentration in patients with cirrhosis: role of splanchnic and renal passage and liver function. Hepatology 1995;21:735-9.

18 Kuddus RH, Nalesnik MA, Subbotin VM, et al. Enhanced synthesis and reduced metabolism of endothelin-1 (ET-1) by hepatocytes - an important mechanism of increased endogenous levels of ET-1 in liver cirrhosis. J Hepatol 2000;33:725-32.
19 Pittet JF, Morel DR, Hemsen A, et al. Elevated plasma endothelin-1 concentrations are associated with the severity of illness in patients with sepsis. Ann Surg 1991;213:261-4.

20 Gandhi CR, Kuddus RH, Nemoto EM, et al. Endotoxin treatment causes an upregulation of the endothelin system in the liver: amelioration of increased portal resistance by endothelin receptor antagonism. J Gastroenterol Hepatol 2001;16:61-9.

21 McMillen MA, Sumpio BE. Endothelins: polyfunctional cytokines. J Am Coll Surgeons 1995; 180:621-37.

22 Yokomori H, Oda M, Ogi M, et al. Enhanced expression of endothelin receptor subtypes in cirrhotic rat liver. Liver 2001;21:114-22.

23 Pannen BHJ, Baver M, Zhang JX, et al. Endotoxin pretreatment enhances portal venous contractile response to endothelin-1. Am J Physiol 1996:39:H7-15.

24 Clozel M, Ramuz H, Clozel J-P, et al. Pharmacology of tezosentan, new endothelin receptor antagonist designed for parenteral use. J Pharmacol Exp Ther 1999;290:840-6.

25 Lebrec D. Animal models in portal hypertension. In: Okuda K, Benhamou JP, eds. Portal hypertension. Clinical and physiological aspects. Tokyo: SpringerVerlag, 1991:101-13

26 Matsukawa A, Kaplan MH, Hogaboam CM, et al. Pivotal role of signal transducer and activator of transcription (Stat) 4 and Stat6 in the innate immune response during sepsis. J Exp Med 2001;193:679-88.

27 Bradford MM. A rapid and sensitive method for the quantification of microgram quantities of protein utilizing the principle of protein-dye binding. Anal Biochem 1976;72:248-54

28 Cahill PA, Forster C, Redmond EM, et al. Enhanced nitric oxide synthase activity in portal hypertensive rabbits. Hepatology 1995;22:598-606.

29 Gadano AC, Sogni P, Heller J, et al. Vascular nitric oxide production during the development of two experimental models of portal hypertension. $J$ Hepatol 1999;30:896-903.

30 Uhlmann D, Uhlmann S, Spiegel HU. Important role for endothelins in acute hepatic ischaemia/reperfusion injury. J Invest Surg 2001;14:31-45.

31 Nishida T, Huang T-P, Seiyama A, et al. Endothelin A-receptor blockade worsens endotoxin-induced hepatic microcirculatory changes and necrosis. Gastroenterology 1998;115:412-20.

32 Bradham CA, Plumpe JR, Manns MP, et al. Mechanism of hepatic toxicity. I. TNF-induced liver injury. Am J Physiol 1998;275:G387-92.

33 Wang JH, Redmond HP, Wu QD, et al. Nitric oxide mediates hepatocyte injury. Am J Physiol 1998;275:G1117-26.

34 Ou J, Carlos TM, Watkins SC, et al. Differential effects of nonselective nitric oxide synthase (NOS) and selective inducible NOS inhibition on hepatic necrosis, apoptosis, ICAM-1 expression, and neutrophil accumulation during endotoxemia. Nitric Oxide 1997;5:404-16.

35 Grobmyer SR, Armstrong RC, Nicholson SC, et al. Peptidomimetic fluoromethylketone rescues mice from lethal endotoxic shock. Mol Med 1999;5:585-94.

36 Wang $\mathrm{H}$, Bloom $\mathrm{O}$, Zhang $\mathrm{M}$, et al. HMG-1 as a late mediator of endotoxin lethality in mice. Science 1999;285:248-51.

37 Calanda T, Echtenacher B, Roy DL, et al. Protection from septic shock by neutralization of macrophage migration inhibitory factor. Nat Med 2000;6:164-70.

38 Bouchon A, Facchetti F, Weigand MA, et al. TREM-1 amplifies inflammation and is a crucial mediator of septic shock. Nature 2001;410:1103-7.

39 Nathan C, Ding A. TREM-1: a new regulator of innate immunity in sepsis syndrome. Nat Med 2001;7:530-2.

\section{EDITOR'S QUIZ: GI SNAPSHOT}

\section{Answer}

From question on page 1824

Histopathology revealed high grade T cell non-Hodgkin's lymphoma involving the entire resected colon, the terminal ileum, and all 17 dissected lymph nodes. Immunophenotyping of the malignant $\mathrm{T}$ cells showed expression of CD3, CD30, and CD4 but CD8 expression was absent. The patient was unfit for chemotherapy and died two months later.

Colonic lymphoma is a rare but recognised complication of ulcerative colitis. Colitis associated colonic lymphoma, unlike sporadic lymphoma, is often multifocal, left sided, high grade, and extensive at diagnosis. Mean age at presentation is 50 years and mean duration of colitis at the time of diagnosis of the lymphoma is 12 years. Most colonic lymphomas are non-Hodgkin's type, arise from mucosa associated lymphoid tissue, and are B cell in origin. $\mathrm{T}$ cell lymphoma is rare in the large bowel but has been described in coeliac disease and following organ transplantation.

This case illustrates the difficulty in differentiating inflammatory bowel disease from colonic lymphoma, which should be considered in patients with resistant disease.

doi: 10.1136/gut.2004.040451 